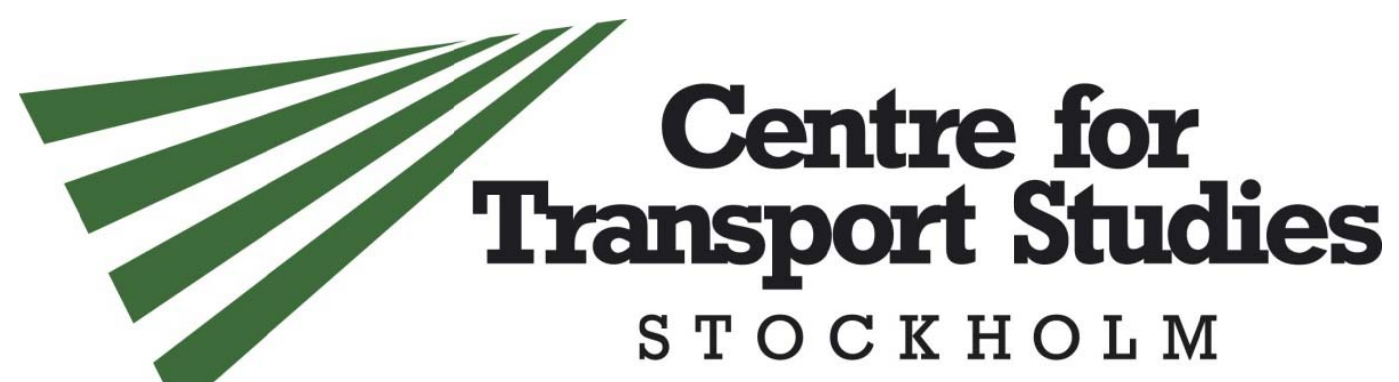

\title{
A long term analysis of the mechanisms underlying children's activity-travel engagements in the Osaka metropolitan area
}

\author{
Yusak O. Susilo - Royal Institute of Technology (KTH) \\ E. Owen D. Waygood - University of the West of England (UWE), Bristol, UK
}

CTS Working Paper 2011: 17

\begin{abstract}
Using a series of conventional large-scale household travel surveys conducted in the Osaka metropolitan area of Japan in 1980, 1990 and 2000 this study examines the mechanisms underlying children's activity and travel engagements and how these mechanisms have changed over time. The results from a structural equation model show that, in the last two decades, children's trip patterns in the Osaka metropolitan area have become more efficient through greater trip chaining. At the same time, the results also show that boys have become less mobile and their non-school activities tend to be in fewer locations than those of girls. Further, Japanese boys are the ones who travelled by car more frequently than girls. Denser built environments, accessibility by rail transport, and a higher number of school trips have constantly reduced the amount of children's private car trips in the last three decades. Moreover, private car availability did not significantly increase the amount of children trip chaining in any observed year. This finding goes against the commonly held belief that public transport is less suitable for trip chaining. This is presumably due to the travel environment created by the well developed transit networks and dense land use in the study area.
\end{abstract}

Keywords: Children, Travel behaviour, Over time changes, SEM, The Osaka metropolitan area

JEL Codes: I18, O18, Z10 



\title{
A long term analysis of the mechanisms underlying children's activity-travel engagements in the Osaka metropolitan area
}

\author{
Yusak O. Susilo, E. Owen D. Waygood* \\ Centre for Transport \& Society, Faculty of the Environment $\mathcal{E}$ Technology, University of the West of England, Frenchay Campus, Bristol BS16 $1 \mathrm{QY}$, United Kingdom
}

\section{A R T I C L E I N F O}

\section{Keywords:}

Children

Travel behaviour

Over time changes

SEM

The Osaka metropolitan area

\begin{abstract}
A B S T R A C T
Using a series of conventional large-scale household travel surveys conducted in the Osaka metropolitan area of Japan in 1980, 1990 and 2000 this study examines the mechanisms underlying children's activity and travel engagements and how these mechanisms have changed over time. The results from a structural equation model show that, in the last two decades, children's trip patterns in the Osaka metropolitan area have become more efficient through greater trip chaining. At the same time, the results also show that boys have become less mobile and their non-school activities tend to be in fewer locations than those of girls. Further, Japanese boys are the ones who travelled by car more frequently than girls. Denser built environments, accessibility by rail transport, and a higher number of school trips have constantly reduced the amount of children's private car trips in the last three decades. Moreover, private car availability did not significantly increase the amount of children trip chaining in any observed year. This finding goes against the commonly held belief that public transport is less suitable for trip chaining. This is presumably due to the travel environment created by the well developed transit networks and dense land use in the study area.
\end{abstract}

(C) 2011 Elsevier Ltd. All rights reserved.

\section{Introduction}

In the past few decades there has been a significant amount of study of adult travel patterns and how these are influenced by socio-demographics, built environment conditions, preferences and attitudes. Those studies produced a general consensus that the denser the urban structure, particularly in combination with a mix of land uses in close proximity, the lower the dependence on the car. A mixed and denser urban structure would have densities that are high enough to support good public transport services and would encourage greater levels of walking and cycling, and enable residents (both adults and children) to make fewer car trips and trips of shorter distances (Waygood and Kitamura, 2009; Ewing and Cervero, 2010). At the same time, some previous studies (Kitamura et al., 1997; Handy et al., 2005; Susilo and Maat, 2007; Mercado and Páez, 2009; Cao et al., 2009; Susilo, 2010) also found that although land use characteristics, such as urban form, have some significance in explaining travel behaviour, individual attitudes are often more strongly associated with travel behaviour than land use policies which promote higher densities. It is evident that land use policies promoting mixed use, higher density developments may not have a material effect on travel demand unless

\footnotetext{
* Corresponding author.

E-mail addresses: yusak.susilo@uwe.ac.uk (Y.O. Susilo), owen.waygood@uwe. ac.uk (E.O.D. Waygood).
}

individuals' attitudes are also changed (Bagley and Mokhtarian, 2002; Susilo et al., 2010).

Previous research has also shown that travel behaviour itself is not built within a day, but is a learning process over one's whole life (Baslington, 2008; Hjorthol and Fyhri, 2009). How we grow up will influence the way we travel, including our perspectives on travel modes and our habits (Lanzendorf, 2003). Age, education and job changes are consistently reported as significantly influencing decisions about residential moves and changes in travel modes throughout an individual's life course (e.g. Courgeau, 1985; Hollingworth and Miller, 1996). Simma and Axhausen (2003) found that the use of a particular travel mode positively influences the usage of the same mode for the rest of an individual's life course, and the usage of other modes negatively. In line with these findings, Naess (2006) argued that children who have used bicycles in their childhood would be more likely to cycle as an adult than their counterparts who grew up travelling predominantly by car. Therefore, in order to understand and predict travel behaviour, it is important to understand its evolution from childhood, how it is modified over time and why. Unfortunately, whilst children's health and their physical activity participation have received significant attention from sociologists, psychologists, and public health researchers (e.g. Bianchi, 2000; Sjolie and Thuen, 2002; Timperio et al., 2004), knowledge about the mechanisms of children's travel and trip making behaviour over a longer time period remains limited.

Most recent studies of children's travel behaviour focus on the journey to school or how activity time influences parents' activity 
travel patterns. For example, using data from the 2001 US National Household Travel Survey (NHTS) McDonald (2006) showed that $36 \%$ of children's trips of less than one mile to school were by private car (an increase from 7\% in 1969), with the percentage of walking and bicycle trips being $55 \%$ within that same distance (a decrease from $87 \%$ in 1969). Whilst limited in scope, previous studies (Sjolie and Thuen, 2002; Lin and Chang, 2010) demonstrate strong links between children's school trip characteristics with school travel distance, quality of the urban form in the neighbourhood and also with the availability of safe routes between home and school locations. For example, using self-reported travel diaries of daily travel in the US, Frank et al. (2007) found that a higher residential density was associated with more walking among 911 year olds. For $16-20$ year olds, short distances to a commercial area and a higher intersection density were associated with more walking. A study in Toronto, Canada found that the residential built environment had more influence on the mode to school than the built environment around the school (Mitra et al., 2010). A study from Taiwan showed that high shade-tree density and high sidewalk coverage encouraged children to walk to school independently, while large city block sizes and increased numbers of intersections discouraged children from walking to school independently (Lin and Chang, 2010).

While urban form and density are important in influencing school travel mode, they may not be the only important factors. Waygood and Kitamura (2009) reported that the cultural expectations in Japan trumped all other factors involved in the school travel decision. All children in the study, from the Osaka metropolitan area, were reported to walk to school despite some living in rural areas located far from the school. In the US, McMillan (2007) pointed out that social environment factors, such as poverty and social cohesion, had a larger influence than urban form. Similar findings are also echoed by McDonald (2007), Alton et al. (2007) and Timperio et al. (2004), studies from the US, England and Australia, respectively.

Given that the built environment conditions parents' activitytravel engagements, and their preferences and attitudes constantly change over time (Hillman et al., 1990; Valentine and McKendrick, 1997; Susilo and Kitamura, 2008), it is reasonable to expect that children's travel will change also - not only for school trips but for the rest of their activity-travel engagements on a given day. For example, there has been a substantial increase in the number of women in the labour force, household sizes have decreased, and the population has been aging in many developed countries. These changes have impacted not only adult travel patterns, but also children's (Bianchi, 2000; Copperman and Bhat, 2007; McDonald, 2008). However, to the authors' knowledge, there has not been a study which explores in a systematic way how children's activity-travel engagements have changed over time.

Most previous studies have only focused on children's school trips as a discrete activity and ignored how the changes of this particular trip purpose have influenced other children's activity-trip engagements, and visa versa. Given that the potential for an individual to engage in events and processes is constrained and depends on a set of circumstances linked to the individual as well as his/her environment (Hägerstrand, 1970; Jones, 1979; Susilo and Axhausen, 2007), it is important to understand how a particular trip purpose influences and shapes children's daily activity engagements and activity time given internal and external constraints. This could help us to not only provide a better prediction of children's future travel patterns, but could also provide insight into how we can intervene and influence children's future travel behaviour.

This study examines the mechanisms underlying children's activity and travel engagements and how the mechanisms have changed over time using a series of conventional large-scale house- hold travel surveys conducted in the Osaka metropolitan area of Japan in 1980, 1990 and 2000, and a structural equation modelling framework, The next section offers a brief review of the changes in the Osaka metropolitan area over time along with the travel data that are used in this study. Section 3 presents the behavioural mechanisms adopted in this study. The results of statistical analyses are discussed in Section 4, whilst the final section presents conclusions.

\section{The Osaka metropolitan area and trends on children's travel patterns}

The data was obtained from conventional large-scale household travel surveys that were conducted in the Osaka metropolitan area of Japan in 1970, 1980, 1990 and 2000, with sampling rates of 2.4-3.0\%. For this longitudinal analysis, the Osaka metropolitan area person trip datasets for the years 1980, 1990, and 2000 were used. The 1970 data is excluded due to the unavailability of accessibility indices and also due to the comparability of the collected data over the observed period, for the subsequent analyses. Scrutinising the data collection method and observed values of the variables, the previous studies on this dataset (e.g. Fukui, 2003) have confirmed that the data between 1980 and 2000 are comparable.

The dataset contains the socio-demographic characteristics of the observed respondents, including children, as well as their household characteristics. Information on children under the age of 15 years is entered by a responsible adult. The data also include the duration, purpose and number of activities and trip engagements of the observed respondents on the observed day and the chosen mode, as well as home and work locations (zone) of the observed individual. ${ }^{1}$ To support our study, these datasets have been supplemented with land use and network data from Fukui (2003) and Susilo and Kitamura (2008). The weighted sample profiles of the person trip dataset can be seen in Table 1, Table 2 shows the activity-travel characteristics for children only.

\subsection{The study area: the Osaka metropolitan area}

The Osaka metropolitan area itself is the second largest in Japan, after the Tokyo metropolitan area, with three core cities of Osaka, Kyoto, and Kobe. Osaka is the largest among the three and is the centre of commerce in this metropolitan area; Kyoto was the ancient capital of Japan established in 794; and Kobe is the maritime centre of the area. The region covers a total area of 11,700 square $\mathrm{km}$ within a radius of about $50-60 \mathrm{~km}$ from the centre of Osaka. With a population totalling about 18.6 million as of 2000, it is one of the largest metropolitan areas in the world. The area has very dense, mixed-use land developments, and has well-developed rail networks. However, within the study area, there are also low density areas that are primarily for agriculture. For a detailed look at the development of urban Japan see Kitamura et al. (2003) and Sorenson (2002).

\subsection{Changes in socio-economic and mobility in the study area}

At the metropolitan level, the residential population in the study area has steadily increased through 2000 , although the rate of growth has visibly declined. Fukui (2003) showed how the residential population in the Osaka metropolitan area has decentralized; the number of younger residents has been increasing in the mixed residential area, while the average age of the population

${ }^{1}$ Unfortunately, due to privacy issues, the household link information between respondents has been removed from the dataset which makes the inclusion of the parents' information impossible. Regaining and incorporating this information to the analysis remains a direction for future study. 
Table 1

Database profiles of the Osaka metropolitan area person trip data.

\begin{tabular}{|c|c|c|c|c|}
\hline Variables & 1970 & 1980 & 1990 & 2000 \\
\hline Number of samples & 56,019 & 326,241 & 323,424 & 312,632 \\
\hline Male [D] & $73.1 \%$ & $46.4 \%$ & $46.1 \%$ & $46.0 \%$ \\
\hline 5-9 years old [D] & $5.9 \%$ & $10.6 \%$ & $6.9 \%$ & $5.9 \%$ \\
\hline $10-14$ years old $[\mathrm{D}]$ & $8.7 \%$ & $9.7 \%$ & $8.2 \%$ & $6.1 \%$ \\
\hline $15-19$ years old [D] & $17.2 \%$ & $7.6 \%$ & $9.0 \%$ & $6.5 \%$ \\
\hline 20-24 years old [D] & $14.2 \%$ & $6.4 \%$ & $7.8 \%$ & $7.4 \%$ \\
\hline $25-34$ years old [D] & $10.9 \%$ & $17.8 \%$ & $12.9 \%$ & $15.9 \%$ \\
\hline 35-44 years old [D] & $14.2 \%$ & $17.1 \%$ & $16.5 \%$ & $12.3 \%$ \\
\hline 45-54 years old [D] & $10.3 \%$ & $13.6 \%$ & $15.8 \%$ & $14.7 \%$ \\
\hline $55-64$ years old [D] & $8.7 \%$ & $8.6 \%$ & $12.3 \%$ & $14.3 \%$ \\
\hline 65 years old or over [D] & $10.0 \%$ & $8.5 \%$ & $10.6 \%$ & $16.9 \%$ \\
\hline Number of household members & 4.31 & 3.56 & 3.42 & 3.34 \\
\hline Family with dependent child [D] & $67.9 \%$ & $59.9 \%$ & $52.2 \%$ & $45.1 \%$ \\
\hline Number of cars per adult household members & 0.28 & 0.33 & 0.37 & 0.40 \\
\hline Driver's license ownership [D] & $29.6 \%$ & $26.3 \%$ & $39.8 \%$ & $50.5 \%$ \\
\hline Resides in commercial area [D] & $3.6 \%$ & $2.8 \%$ & $3.1 \%$ & $2.9 \%$ \\
\hline Resides in mixed commercial area [D] & $24.3 \%$ & $24.8 \%$ & $25.2 \%$ & $30.0 \%$ \\
\hline Resides in mixed residential [D] & $37.1 \%$ & $63.6 \%$ & $61.8 \%$ & $60.3 \%$ \\
\hline Resides in autonomous city [D] & $33.6 \%$ & $7.6 \%$ & $9.7 \%$ & $6.1 \%$ \\
\hline Resides in undeveloped area [D] & $1.5 \%$ & $1.2 \%$ & $0.3 \%$ & $0.7 \%$ \\
\hline Worker [D] & $46.0 \%$ & $43.0 \%$ & $46.1 \%$ & $45.7 \%$ \\
\hline Non-worker [D] & $20.8 \%$ & $29.1 \%$ & $29.0 \%$ & $34.2 \%$ \\
\hline Student $[\mathrm{D}]$ & $33.2 \%$ & $27.9 \%$ & $24.8 \%$ & $20.1 \%$ \\
\hline Average number of trip/day & 1.78 & 2.09 & 2.05 & 2.15 \\
\hline
\end{tabular}

Note: [D] indicates a $0-1$ dummy variable.

Table 2

Travel characteristics of children in the Osaka metropolitan area.

\begin{tabular}{|c|c|c|c|c|c|c|}
\hline & \multicolumn{3}{|l|}{ Children } & \multicolumn{3}{|c|}{ All samples } \\
\hline & 1980 & 1990 & 2000 & 1980 & 1990 & 2000 \\
\hline Total number of trips/day & 2.39 & 2.34 & 2.47 & 2.09 & 2.05 & 2.15 \\
\hline Number of compulsory trips/day & 0.97 & 0.97 & 0.94 & 0.70 & 0.72 & 0.64 \\
\hline Number of entertainment and other visits/day & 0.25 & 0.24 & 0.34 & 0.45 & 0.45 & 0.58 \\
\hline Time expenditure for all activities (min) & 425.0 & 438.4 & 441.9 & 346.2 & 337.3 & 319.1 \\
\hline Total travel time (min) & 43.1 & 47.9 & 46.9 & 46.5 & 50.6 & 46.1 \\
\hline Time expenditure for compulsory activities (min) & 399.4 & 415.0 & 408.5 & 281.1 & 292.9 & 264.1 \\
\hline Time expenditure for non-compulsory activities (min) & 22.1 & 23.4 & 33.4 & 44.2 & 44.4 & 55.0 \\
\hline Number of visits/day & 1.21 & 1.20 & 1.29 & 1.10 & 1.13 & 1.21 \\
\hline Number of trip chains/day & 1.17 & 1.14 & 1.18 & 0.99 & 0.92 & 0.94 \\
\hline Average number of visits/trip chain & 1.03 & 1.05 & 1.09 & 1.11 & 1.22 & 1.29 \\
\hline
\end{tabular}

Note: "Compulsory trips" refer to those trips made to engage in compulsory activities such as work and school, and they are not necessarily made from the home base. "Non-compulsory trips" are those made to engage in out-of-home non-compulsory activities (e.g. shopping and entertainment).

is aging in neighbourhoods closer to the nuclei of the metropolis. The average number of vehicles per household in the Osaka metropolitan area increased from 0.41 in 1970 to 0.66 in 1980, 0.88 in 1990 , and 0.97 in 2000 . The area, which is densely populated and well-served by public transit, has had a lower rate of vehicle ownership than the nationwide average of 1.13 vehicles per household in 2000. The more built up parts of the metropolitan area, including commercial centres and mixed commercial areas, have very low rates of motorization. Car use has remained practically unchanged among commercial and mixed-commercial (more jobs than residents) areas, and the car share of all household trips has increased only slightly in urban mixed-residential (more residents than jobs) areas, even when household life-cycle stage is considered (Sun et al., 2009). On the other hand, more recently developed areas on the periphery in general show higher levels and faster growth rates of vehicle use. With the increase in the fraction of private car trips there has been a decline in the share of public transit use in those areas, private car trips are starting to dominate recently urbanizing areas (Kitamura et al., 2003; Kitamura and Susilo, 2005). However, this pattern has not yet influenced children's travel to school, but is emerging in after school travel with more children in those less built up areas leaving school by car than in more densely populated areas (Waygood and Kitamura, 2009).

\subsection{Trends on children's activity-travel pattern in the study area}

The weighted children's and general population's travel characteristics in the 1980, 1990 and 2000 datasets are summarized in Table 2. Children in this study are defined as individuals who are less than 20 years old. This age definition is taken because in Japan 20 years is the age of adulthood. ${ }^{2}$ The data was pre-coded in 5 years age groupings, so it was not possible to further refine this aspect. Information for children under the age of five is not gathered. As can be seen in the table, the number of daily trips, especially non-compulsory purpose trips, for both children and the general population has increased in the last two decades. The number of children's daily trips has increased by about 3.3\% between 1980 and 2000, which is similar to the increased rate for the average population's daily trips (3.1\%). Within the same period, children's non-compulsory trips have increased $38 \%$, while the average population increase rate was approximately $29 \%$. Overall, children make more trips, but spend less time travelling than the average population, which is not surprising given the school location in this area of Japan tends to be within $0.5 \mathrm{~km}$ walking dis-

\footnotetext{
${ }^{2}$ The legal age to drive a moped in Japan is 16 , and the age to drive a car is 18 .
} 


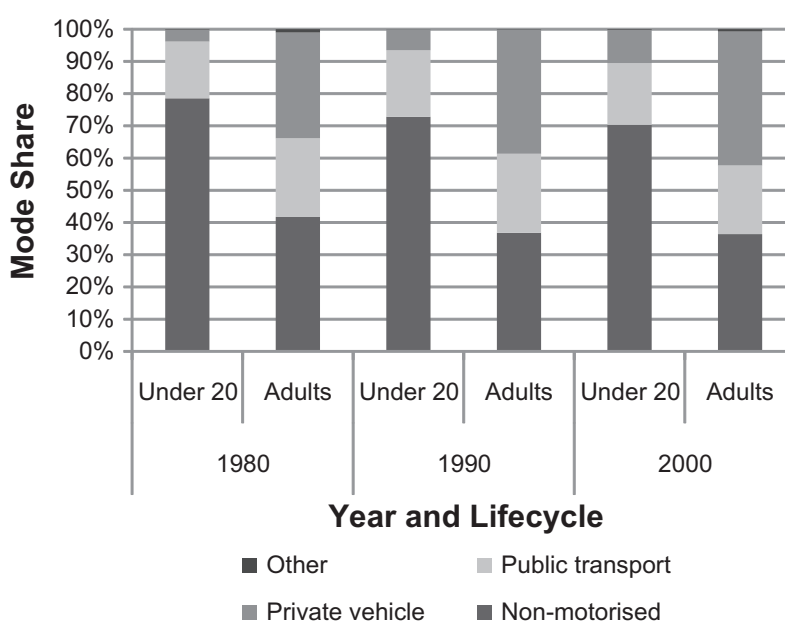

Fig. 1. Travel mode share in the Osaka metropolitan area in 1980, 1990 and 2000.

tance (10-15 min walk) from the home location (Waygood and Susilo, 2011). Children in the Osaka metropolitan areas also chain fewer trips on their daily trip patterns than the average population. ${ }^{3}$ Nevertheless, the table also shows that both children and the general population tend to increase the efficiency of their trip patterns by doing more visits per trip.

In terms of travel mode share, as shown by Fig. 1, adults have a much more significant private car share than children. As children are not legally allowed to use private cars until the age of 18 in Japan this should be the case if children have high levels of independent travel. Whilst adults have moved more to private motor car use between 1980 and 2000, children have seen greater growth in mass transit (more than doubled) while retaining a roughly $70 \%$ mode share for non-motorized travel as late as $2000{ }^{4}$

It is clear from the discussions above that people's travel behaviours, including children, have been continuously changing over time. However, as shown in Table 2 and Fig. 1, the changing patterns of children are unique compared to those of adults. Whilst the over time changes of adults' travel behaviours have been examined recently (e.g. Bamberg, 2006; Susilo and Kitamura, 2008), to the authors' knowledge, only a few studies have examined temporal changes in children's travel behaviour (e.g. McDonald, 2006; Hillman et al., 1990), and most of the previous studies only focused on a particular child's trip purpose and ignored how the over time changes of this particular trip purpose influence other daily activity-trip engagements.

Given that an individual's potential to engage in events and processes is constrained and depends on a set of circumstances linked to the individual as well as to her/his environment (Hägerstrand, 1970; Jones, 1979; Susilo and Dijst, 2009), it is important to understand how a change in a particular trip purpose would enable or constrain children to engage in other trips and activities within a given day. These constraints define the set of spatio-temporal opportunities children have for travelling to activity places and to participate in activities (Susilo and Dijst, 2010). For example, the probability of whether a child would be able to engage in a certain activity depends on whether s/he would have time to travel to the location and spend a reasonable amount of time on the activity. Shorter travel times (resulting from shorter distances and/or high-

\footnotetext{
${ }^{3}$ A trip chain is defined in this study as a series of trips that starts, and ends, at the home base in which one or more destinations are visited.

${ }^{4}$ As children in this paper is defined as under 20 years old (because of the limitation in recording the dataset and the cultural definition of adult being 20 years old in Japan), it is important to remember that the analysis included the independent mobility of teenagers.
}

er speeds) could mean that more time is allocated to activities. A change in one parameter (e.g. number of compulsory trips) may start a chain reaction that changes other travel parameters (e.g. number of non-work visits, available travel time, travel mode etc.) which may be unique for different groups of children at different levels of development. In the next section, we will examine how these relationships influence each other and how these have changed over the 20 years of observation within one integrated framework using a structural equation modelling.

\section{The model structure}

A model system of children's activity engagement and travel is developed in this study taking into consideration pertinent elements that influence their activity-travel engagements. The relationships are synthesised and hypothesised based on the literature discussed above. The model includes as endogenous variables: their constraints from school commitments, the number of discretionary activities, the number of trip chains, and the proportion of private car trips, compared to the other modes, on a given day. The model system embodies the causal structure postulated for these variables. The proposed model structure can be seen in Fig. 2. An arrow indicates the direction of a hypothesised causal relationship which is developed based on previous literatures findings and explained as follow.

It is assumed that the amount of children's walking and cycling trips depends on: (1) their socio demographic characteristics, (2) their compulsory commitments (number of school trips ${ }^{5}$ and duration), (3) the opportunities that are available based on their built environment conditions and (4) their ability to chain their trips and spend time in non-work/school activities. ${ }^{6,7}$ Instead of using the proportion of child walking and cycling trips on a given day, in this model the proportion of private car trips is used as the dependent variable. The reason for using this dependent variable is because focusing on walking and cycling trips in the Japanese case may undermine a significant proportion of children who used public transport (which involves walking and cycling as well). Therefore, whilst the proportion of car trips is used as the dependent variable, the analysis will focus on what variables discourage children's travel by private car and how this relates to their daily non-compulsory activity engagements and trip chains.

As expected, synthesising and hypothesising a model framework of children's trip and activity making behaviour produced a complex structure. To analyse this model framework, a structural equation model is used. Structural equation modelling (SEM) is a powerful technique for the analysis of multiple simultaneous causal relationships among endogenous variables, and between endogenous and exogenous variables. In fact, numerous studies using SEM methods have been conducted on travel demand and travel behaviour (e.g. Golob, 2003; Choo and Mokhtarian, 2005), but they have mainly focused on the analysis of adult travel behaviour. Fyhri and Hjorthol (2009) used an SEM to analyse children's

\footnotetext{
${ }^{5}$ School trips is used here to refer to any trip to the school location. This would include trips to the school for after-school activities such as clubs.

6 We acknowledge that children's travel mode is also influenced by children's and parents' attitudes towards walking and cycling. However, unfortunately, this information is not available within these datasets. Using a separate data set from the same area of Japan, Waygood (2009) did not find any correlation between children's attitudes to modes and their use.

7 Given that children's activity-travel engagements in the US are influenced by the parents' activity-travel engagements (Bianchi, 2000; Copperman and Bhat, 2007) parents' activity-travel engagements should be included in the model framework in Fig. 2. Unfortunately, as mentioned earlier, due to privacy issues, the household link information between respondents has been removed from the dataset which makes the inclusion of the parents' information impossible. This would remain as a direction future study.
} 


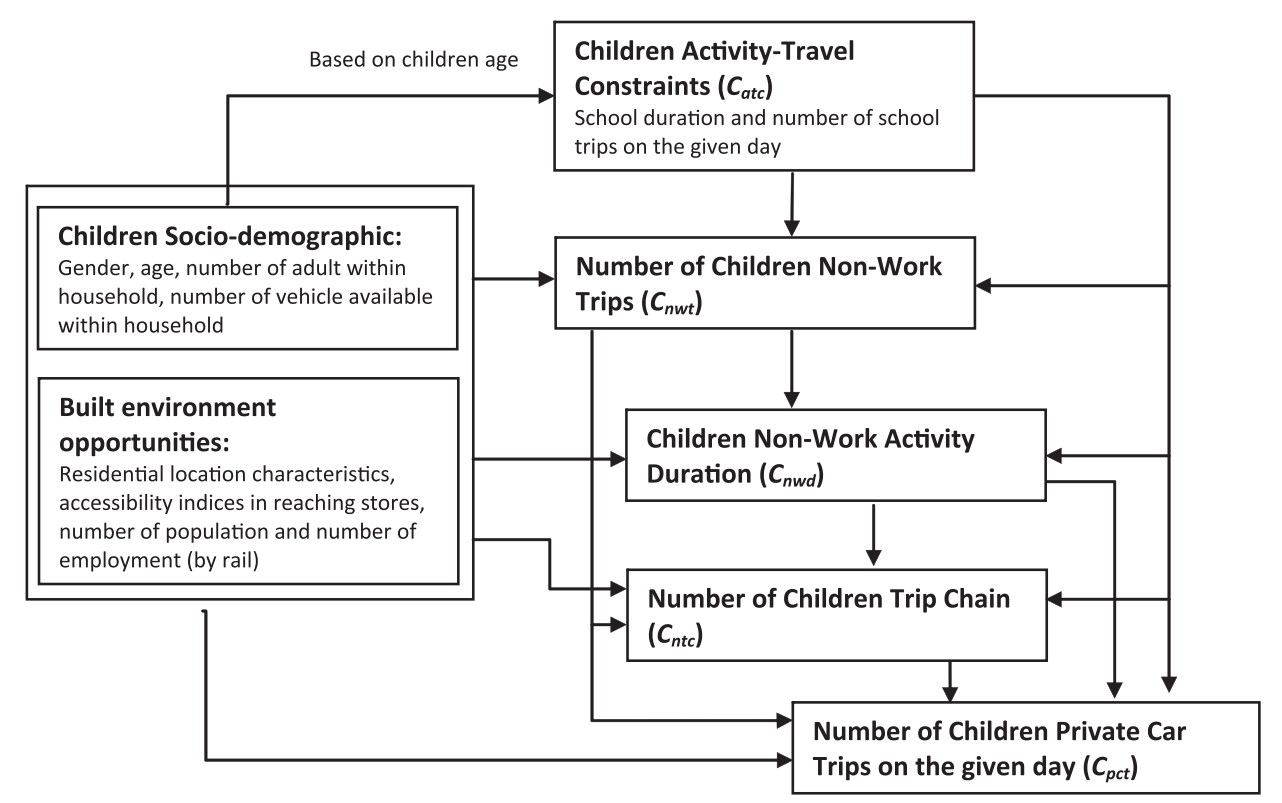

Fig. 2. The structure of the model.

independent travel in Norway. However they used a cross-sectional design and did not include activity participation in the analysis. This is essential in understanding the reasons underlying children's trip making behaviour.

Assuming $R=$ the vector of variables representing the children residential areas, including accessibility indices, and $W=$ the vector of children's socio demographic attributes and let $C_{a t c}=$ children's school activity constraints, $C_{n w t}=$ number of children's non-work trips, $C_{n w d}=$ duration of children's non-work activities, $C_{n t c}=$ number of trip chains, and $C_{n m t}=$ number of children's private car trips then the model system on Fig. 2 may be formulated in general form as follows:

$$
\left\{\begin{array}{l}
C_{a t c}=f C_{a t c}(\text { school duration, number of school trips) } \\
C_{n w t}=f C_{n w t}\left(C_{a t c}, R, W\right) \\
C_{n w d}=f C_{n w d}\left(C_{a t c}, C_{n w t}, R, W\right) \\
C_{n t c}=f C_{n t c}\left(C_{a t c}, C_{n w t}, C_{n w d}, R, W\right) \\
C_{p c t} f C_{p c t}\left(C_{a t c}, C_{n w t}, C_{n w d}, C_{n w t}, R, W\right)
\end{array}\right.
$$

It is assumed in this model system that children's school activity engagements, like the number of school trips and school duration, $C_{a t c}$, act as an explanatory variable that influences the number of children's non-compulsory trips, $C_{n w t}$, which together with children's school constraints will influence the duration of non-compulsory activities that children would be able to do on the given day, $C_{n w d}$. All of these variables will influence children's trip chain patterns, $C_{n t c}$, and also their propensity to use a private car (chauffeured or otherwise) as their travel mode, $C_{p c t}$.

The vector $R$ contains two types of measures that represent residential and work area characteristics: residence area type and accessibility indices. The residence area type that is used is based on the urban area classification scheme developed by Fukui (2003) and defined as follows:

- Highly commercial area: highest densities of commercial development and a higher daytime population compared to the night-time population.

- Mixed commercial areas: a high density of commercial development, though not as high as a commercial area and have residential development as well, often of a high density. Less distinction between day and night populations.
- Mixed residential areas: do not have sufficient work for the population, most residents commute elsewhere. Have a larger night-time than day-time population.

- Autonomous areas: roughly an equal amount of residential and commercial development, allows residents to live and work within the area. No difference in day/night population. Population density lower than for mixed residential areas. Separate from the main urban development, typically includes towns in agricultural areas.

- Undeveloped (rural) area: low density commercial and residential development. Often represent smaller farming communities.

The accessibility indices that were used in this study are similar with those used by Kitamura and Susilo (2005) and are defined as:

$I_{i}^{m p}=\sum_{j} \frac{A_{j}^{p}}{\left(t_{i j}^{m}\right)^{2}}$

where $I_{i}^{m p}=$ the accessibility index at zone $i$ for activity type $p$ by mode $m, A_{j}^{p}=$ the attraction measure of zone $j$ for activity type $p$, $t_{i j}^{m}=$ the mean travel time between zones $i$ and $j$ by mode $m$, and $m=$ private car, or rail; and $p=$ work (employment used as the attraction measure), social (population as the attraction measure), or shopping (retail establishments as the attraction measure). ${ }^{8,9}$

\section{SEM analysis results}

The estimation results of the models can be seen in Tables 3-5 for the 1980, 1990 and 2000 models, respectively, the discussion of results is provided in the following section. 'Children aged 15-19' and 'Resides at undeveloped (rural) areas' were used as reference

\footnotetext{
${ }^{8}$ Whilst recent research (Páez et al., 2010) shows that the meaning of accessibility is different for different age cohorts, which may be the case between younger and older children, to avoid any confusion of the accessibility interpretation between age groups, in this study we only use one accessibility definition as described in Eq. (2). The use of unique accessibility definitions for each age cohort remains as a recommendation for future research.

${ }^{9}$ The distance-decay exponential represents our perceived accessibility (cognitive distance) which decreases in an exponential relationship with the travel distance.
} 
variables for age and residential location dummy variables. An explanatory variable would be considered to significantly associate with the dependent variable at $\alpha=5 \%$ if the absolute $t$-statistic value equals or is larger than 1.96. The magnitude and direction of influence (e.g. positively/negatively influence the dependent variable) are shown by the value and sign of the coefficient estimates.

\subsection{Changes in impact of the school engagements on child trip making}

Children between 10 and 14 years of age made more school trips and spent more time in school than their younger (5-9 years old) and older (15-19 years old) counterparts (Tables 3-5). For example, in 2000 (Table 5), on average, 10-14 years old children spent 44 and $73 \mathrm{~min}$ longer $(44+29 \mathrm{~min})$ in school than older (15-19 years old) and younger (5-9 years old) children. They also made 0.14 more school trips than older children. Since school engagements, which are represented by school trips and durations, are compulsory for the children, these school engagements will presumably become constraints for children in choosing slower travel modes (e.g. walking and cycling) as their time would be more restricted. However, at the same time, these constraints will act as a catalyst which could encourage children to chain their trips within their school trips. This type of activity-travel organization is, in theory, highly supported by a Japanese built environment condition characterized as having a high level of mixed land-use. Whilst the trends are similar across years, differences between age groups are smaller in later years. Presumably this is because the length of elementary/grammar school days recently has increased more than high school, as expectations of children's academic skills increase and non-traditional class subjects were added to the curriculums in 1989 (The Library of Congress, 1994).

As expected, the estimation results show that compulsory activity engagement is one of the most significant variables associated with the number of non-school visits, the number of trip chains and travel mode choice. In the 1980s and 1990s, a higher number of school trips and longer school duration reduced the number of children's non-school trips (e.g. shopping, leisure and social trips), reduced the duration of these non-school activities, but increased the amount of trip chaining that children were involved in. While the longer school duration also encouraged more travel by private car, a higher number of school trips actually encouraged travel modes other than private car.

Moreover, whereas the behavioural interaction in 2000 is similar with 1980s and 1990s, a higher number of school trips among children in 2000 coincided with an increase in the number of non-school trips. This may show that, in the last two decades, children in the Osaka metropolitan area have become more resilient having increased the efficiency of their trip patterns by chaining extra trips onto their school trips whenever possible.

\subsection{Changes in non-school activity engagements}

Whilst there were not any significant gender differences in nonschool trip making in 1980, in 1990 and 2000, boys made fewer non-school trips than girls. Moreover, where as boys spent a longer duration in non-school activities than girls in 1980 and 1990, the difference became smaller and less significant in later years (the difference only becomes significant at $\alpha=10 \%$ in 2000; boys spent 1.9, 1.2 and 0.8 min longer on non-school activities than girls in 1980,1990 , and 2000, respectively). This shows that over the past 20 years boys have become less mobile and they tend to spend their non-school activity in fewer locations than girls. The difference between the sexes on time spent in out-of-home non-school activities is getting smaller over time.

Interestingly, the estimation results also show that younger children (5-9 years old) are becoming more travel active (making more shorter-duration trips) relative to their older counterparts. Over the last 20 years they have increased the number of their non-school trips, but still spend much less time on non-school activities than older children. These younger children (5-9 years old) spent 7.5, 9.5, $15.5 \mathrm{~min}$ less for non-school activities than $15-19$ years old youth in 1980, 1990 and 2000, respectively, but at the same time, they made $0.09,0.12,0.13$ trips more than the 15-19 years old youth.

A larger number of adults within a household reduced the number of children's non-school trips and the influence was stronger in more recent years. Presumably it is because a larger number of adult household members would enable the adults to share their intra-household trip responsibilities between themselves. Children might also be less likely to accompany their parents in doing errands because an alternative caregiver is at home.

There is a strong indication that children residing in mixed areas tend to do more non-school trips, whilst the ones who live in highly commercial areas tend to spend more time in non-school activities. This relationship is significantly shown by the 1980 and 1990 respondents. However, the relationships are not as clear for the year 2000 .

The estimation results also show that more frequent non-school activity trips would increase the amount of trip chaining but also potentially increase the amount of private car trips taken by children.

\subsection{Children's trip chaining behaviour}

The estimation results show that boys made more trip chains than girls and that the gap between the sexes in terms of trip chains has widened over time. Whilst younger children $(5-9$ years old) were involved in more trip chains than older children in 1980 and 1990, 10-14 years old children have increased their trip chaining over time. By the year 2000 they made the same number of trip chains per day as 5-9 year old children.

Interestingly, private car availability did not significantly (at $\alpha=5 \%$ ) increase the amount of children trip chaining in any observed year. The results here are consistent with a similar analysis in the Osaka metropolitan area which focused on commuters (Susilo and Kitamura, 2008), which runs entirely counter to the common belief that private car travellers are more mobile and chain trips more often (e.g., Strathman and Dueker, 1995). This is presumably due to the travel environment created by the well developed transit networks and dense land use in the study area. In Japanese urban areas such as the Osaka metropolitan area, public transport terminals provide superb access to a large number of opportunities. This environment apparently encourages public transport users, including children, to engage in more activities and pursue complex commutes with non-work/school activities by transit. The common belief that public transport is less suitable for trip chaining than the private car evidently does not seem to apply in the metropolitan areas of Japan. The observation here supports the notion that activity engagement and travel patterns are conditioned by transportation networks and land use developments.

\subsection{Proportion of travel using private car}

Against the conventional wisdom and past research (e.g. Hillman et al., 1990) that suggests that girls are protected more than boys, the estimation results show that in the last two decades, boys are travelling by car more frequently. It is not clear from this research why this might be. However, it is important to note that girls in this development pattern are not as car dependent as their western counterparts appear to be (e.g. Babey et al., 2009; Fyhri and Hjorthol, 2009; Page et al., 2009). From an age perspective, 
Table 3

Estimation results for year 1980 dataset.

\begin{tabular}{|c|c|c|c|c|c|c|c|c|c|c|c|c|}
\hline & \multicolumn{2}{|c|}{$\begin{array}{l}\text { Number of } \\
\text { compulsory } \\
\text { (school) trips }\end{array}$} & \multicolumn{2}{|c|}{$\begin{array}{l}\text { Duration of } \\
\text { compulsory } \\
\text { (school) activity }\end{array}$} & \multicolumn{2}{|c|}{$\begin{array}{l}\text { Number of non } \\
\text { school/work visits }\end{array}$} & \multicolumn{2}{|c|}{$\begin{array}{l}\text { Duration of non } \\
\text { school/work visits }\end{array}$} & \multicolumn{2}{|c|}{ Number of trip chain } & \multicolumn{2}{|c|}{$\begin{array}{l}\text { Proportion of private } \\
\text { car trips on the given } \\
\text { day }\end{array}$} \\
\hline & Coeff. & $\begin{array}{l}t- \\
\text { Stats. }\end{array}$ & Coeff. & $t$-Stats. & Coeff. & $t$-Stats. & Coeff. & t-Stats. & Coeff. & t-Stats. & Coeff. & $t$-Stats. \\
\hline Intercept & 0.84 & 771.92 & 415.12 & 695.72 & 0.53 & 43.67 & 45.40 & 47.36 & 0.28 & 44.69 & 0.19 & 55.58 \\
\hline Male & & & & & -0.0003 & -0.08 & 1.893 & 7.43 & 0.005 & 3.23 & 0.012 & 13.47 \\
\hline Age between 5 and 9 years old & 0.125 & 82.03 & -69.81 & -83.67 & 0.089 & 24.89 & -7.564 & -26.88 & 0.074 & 41.06 & 0.002 & 2.02 \\
\hline Age between $10-14$ years old & 0.149 & 96.19 & 34.62 & 40.67 & 0.114 & 31.70 & 0.366 & 1.29 & 0.024 & 13.13 & -0.019 & -19.16 \\
\hline Number of vehicle per household & & & & & -0.013 & -9.42 & -0.196 & -1.86 & 0.0002 & 0.26 & 0.017 & 46.46 \\
\hline Number of adult within household & & & & & -0.007 & -4.58 & -0.282 & -2.41 & -0.002 & -2.71 & -0.004 & -10.46 \\
\hline Resides in highly commercial areas & & & & & 0.026 & 2.01 & 4.267 & 4.11 & -0.009 & -1.29 & -0.013 & -3.49 \\
\hline Resides in mixed commercial areas & & & & & 0.040 & 9.17 & 1.160 & 3.42 & 0.012 & 5.69 & -0.010 & -8.79 \\
\hline Resides in autonomous cities & & & & & 0.010 & 1.96 & -0.611 & -1.58 & 0.016 & 6.56 & 0.001 & 0.39 \\
\hline Resides in mixed residential areas & & & & & 0.021 & 6.10 & 0.070 & 0.26 & 0.004 & 2.42 & -0.010 & -10.21 \\
\hline Accessibility to employment by rail & & & & & 0.00001 & 3.86 & -0.003 & -14.14 & -0.00003 & -18.63 & -0.000003 & -3.70 \\
\hline Accessibility to population by rail & & & & & -0.00002 & -11.81 & -0.0002 & -1.11 & -0.000014 & -15.75 & -0.00001 & -28.70 \\
\hline Accessibility to stores by rail & & & & & 0.002 & 16.66 & 0.093 & 11.38 & 0.0024 & 46.61 & 0.001 & 23.64 \\
\hline $\begin{array}{l}\text { Number of compulsory (school) } \\
\text { trips }\end{array}$ & & & & & -0.159 & -22.19 & -14.280 & -25.27 & 0.397 & 109.71 & -0.190 & -90.20 \\
\hline $\begin{array}{l}\text { Duration of compulsory (school/ } \\
\text { part time works) (in minutes) }\end{array}$ & & & & & -0.0006 & -43.64 & -0.065 & -62.56 & 0.0007 & 102.15 & 0.00005 & 11.57 \\
\hline Number of non school/work trips & & & & & & & 77.334 & 300.82 & 0.641 & 278.67 & 0.009 & 5.19 \\
\hline $\begin{array}{l}\text { Duration of non school/work trips } \\
\text { (in minutes) }\end{array}$ & & & & & & & & & 0.0012 & 59.16 & 0.000002 & 0.16 \\
\hline Number of trip chain & & & & & & & & & & & 0.007 & 3.89 \\
\hline \multicolumn{5}{|c|}{$N=91,713$ children; where the fitness indicators of the model show: } & \multicolumn{4}{|c|}{ CMIN, $d f$} & \multicolumn{2}{|c|}{ RMSEA } & & $P$ \\
\hline Default model & \multicolumn{4}{|c|}{102} & \multicolumn{4}{|c|}{$12,44,838,87$} & \multicolumn{2}{|c|}{0.390} & & .0000 \\
\hline Saturated model & \multicolumn{4}{|c|}{189} & \multirow{2}{*}{\multicolumn{4}{|c|}{$14,61,945,171$}} & \multirow{2}{*}{\multicolumn{2}{|c|}{0.302}} & & \\
\hline Independence model & & 18 & & & & & & & & & & .0000 \\
\hline
\end{tabular}

Note: 'Children aged 15-19' and 'Resides at undeveloped (rural) areas' were used as reference variables for age and residential location dummy variables.

Table 4

Estimation results for year 1990 dataset.

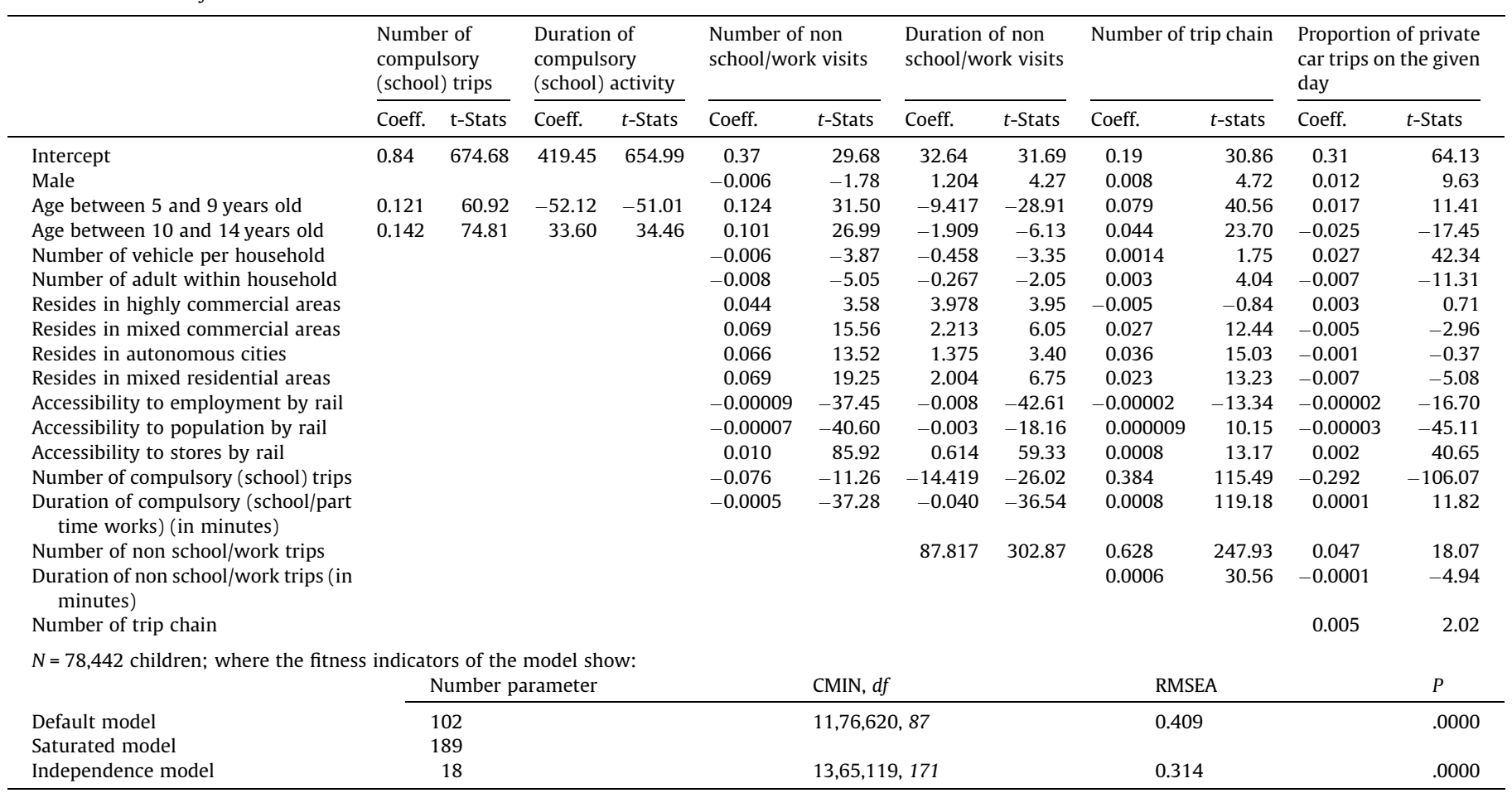

Note: 'Children aged 15-19' and 'Resides at undeveloped (rural) areas' were used as reference variables for age and residential location dummy variables.

10-14 year old children are the ones who consistently travel least by private car whilst 5-9 years old children are the ones who consistently use the private car more in the last 20 years. Car availabil- ity and more trip chains increased the amount of car trips. However, it may be that those trips are also for the parent, rather than the child. Waygood (2011) found that the majority of accom- 
Table 5

Estimation results for year 2000 dataset.

\begin{tabular}{|c|c|c|c|c|c|c|c|c|c|c|c|c|}
\hline & \multicolumn{2}{|c|}{$\begin{array}{l}\text { Number of } \\
\text { compulsory } \\
\text { (school) trips }\end{array}$} & \multicolumn{2}{|c|}{$\begin{array}{l}\text { Duration of } \\
\text { compulsory } \\
\text { (school) activity }\end{array}$} & \multicolumn{2}{|c|}{$\begin{array}{l}\text { Number of non } \\
\text { school/work visits }\end{array}$} & \multicolumn{2}{|c|}{$\begin{array}{l}\text { Duration of non } \\
\text { school/work visits }\end{array}$} & \multicolumn{2}{|c|}{$\begin{array}{l}\text { Number of trip } \\
\text { chain }\end{array}$} & \multicolumn{2}{|c|}{$\begin{array}{l}\text { Proportion of private } \\
\text { car trips on the given } \\
\text { day }\end{array}$} \\
\hline & Coeff. & $t$-Stats & Coeff. & $t$-Stats & Coeff. & $t$-Stats & Coeff. & $t$-Stats & Coeff. & $t$-Stats & Coeff. & $t$-Stats \\
\hline Intercept & 0.84 & 564.83 & 403.96 & 504.69 & 0.61 & 37.96 & 39.12 & 29.31 & 0.12 & 15.30 & 0.14 & 24.20 \\
\hline Male & & & & & -0.019 & -3.86 & 0.750 & 1.83 & 0.018 & 7.43 & 0.004 & 2.27 \\
\hline Age between 5 and 9 years old & 0.125 & 56.17 & -28.57 & -23.81 & 0.125 & 22.94 & -15.530 & -34.39 & 0.084 & 31.13 & 0.059 & 29.71 \\
\hline Age between 10 and 14 years old & 0.138 & 62.91 & 43.89 & 37.03 & 0.099 & 18.08 & -5.226 & -11.58 & 0.084 & 31.14 & -0.024 & -12.08 \\
\hline Number of vehicle per household & & & & & 0.004 & 1.65 & -0.207 & -1.04 & 0.0003 & 0.24 & 0.031 & 36.56 \\
\hline Number of adult within household & & & & & -0.024 & -10.72 & 0.050 & 0.27 & 0.006 & 5.22 & -0.009 & -11.53 \\
\hline Resides in highly commercial areas & & & & & 0.021 & 1.11 & -1.722 & -1.11 & 0.034 & 3.66 & -0.049 & -7.38 \\
\hline Resides in mixed commercial areas & & & & & 0.011 & 1.77 & -2.135 & -4.33 & 0.031 & 10.56 & -0.055 & -25.70 \\
\hline Resides in autonomous cities & & & & & 0.044 & 5.12 & -0.795 & -1.13 & 0.024 & 5.73 & -0.006 & -1.87 \\
\hline Resides in mixed residential areas & & & & & 0.016 & 3.09 & -1.158 & -2.68 & 0.027 & 10.41 & -0.034 & -18.05 \\
\hline $\begin{array}{l}\text { Accessibility to employment by } \\
\text { rail }\end{array}$ & & & & & 0.000002 & 1.20 & 0.0006 & 4.68 & -0.000003 & -4.22 & -0.000002 & -2.93 \\
\hline Accessibility to population by rail & & & & & 0.000003 & 2.54 & 0.0004 & 4.03 & 0.000003 & 4.53 & -0.000004 & -9.16 \\
\hline Accessibility to stores by rail & & & & & 0.0002 & 1.79 & -0.038 & -4.80 & 0.00006 & 1.33 & -0.0002 & -4.56 \\
\hline $\begin{array}{l}\text { Number of compulsory (school) } \\
\text { trips }\end{array}$ & & & & & 0.099 & 10.04 & -3.526 & -4.36 & 0.561 & 116.60 & -0.184 & -47.51 \\
\hline $\begin{array}{l}\text { Duration of compulsory (school/ } \\
\text { part time works) (in min) }\end{array}$ & & & & & -0.001 & -50.65 & -0.060 & -39.16 & 0.0005 & 57.61 & 0.0002 & 28.98 \\
\hline Number of non school/work trips & & & & & & & 84.219 & 247.83 & 0.525 & 181.68 & 0.068 & 26.13 \\
\hline $\begin{array}{l}\text { Duration of non school/work trips } \\
\text { (in minutes) }\end{array}$ & & & & & & & & & 0.0008 & 32.35 & 0.0001 & 8.07 \\
\hline Number of trip chain & & & & & & & & & & & 0.022 & 7.32 \\
\hline \multicolumn{13}{|c|}{$N=58,809$ children; where the fitness indicators of the model show: } \\
\hline & \multicolumn{4}{|c|}{ Number parameter } & \multicolumn{4}{|c|}{ CMIN, $d f$} & \multicolumn{2}{|c|}{ RMSEA } & & $P$ \\
\hline Default model & \multirow{2}{*}{\multicolumn{4}{|c|}{$\begin{array}{l}102 \\
189\end{array}$}} & \multicolumn{4}{|c|}{$480,411,87$} & \multicolumn{2}{|c|}{0.306} & & .0000 \\
\hline Saturated model & & & & & \multirow{2}{*}{\multicolumn{3}{|c|}{$605,994,153$}} & & & & & \\
\hline Independence model & \multicolumn{2}{|r|}{36} & & & & & & & \multicolumn{2}{|l|}{0.259} & & .0000 \\
\hline
\end{tabular}

Note: 'Children aged 15-19' and 'Resides at undeveloped (rural) areas' were used as reference variables for age and residential location dummy variables.

panied trips for 10 and 11 year olds in this area was for shopping or to restaurants, suggesting that they are errands run by the parent or family trips, rather than serve passenger trips often seen in the western research (e.g. McDonald, 2006; Stefan and Hunt, 2006). Built environment aspects such as better accessibility by rail to population and employment centres reduced the amount of private car trips by children and children who lived in mixed commercial and mixed residential areas are the ones who consistently travelled less by car.

Denser built environments (apart from highly commercial area residents in the 1990 dataset), accessibility by rail (to employment, stores, and other people), and a higher number of school trips consistently associate with fewer private car trips. In contrast, a longer school duration, more non-school trips and a higher number of trip chains have consistently increased the proportion of children's private car trips over the three observed periods.

\section{Conclusions}

Given that children's travel behaviour is a dynamic process which keeps evolving, understanding of the reasons underlying the mechanisms of children's activity-travel patterns are essential in order to provide a better projection of children's future travel patterns and also in predicting how children's travel would change in response to various transport policy measures. Using a series of conventional large-scale household travel surveys conducted in the Osaka metropolitan area of Japan in 1980, 1990 and 2000, this study explored the changes over time of children's activity-travel patterns. The results show that children's travel behaviour is a dynamic process which keeps changing. Whilst there are some trips and activity parameters which are changing over time, there are some relationships which remain constant over long term periods.
For example, a higher number of school trips and longer school duration among children in 1980 and 1990 associated with fewer and shorter non-school trips (e.g. shopping, leisure and friend visit trips) and increased the amount of trip chaining. However, this is not the case for children from the year 2000 data. Model coefficients from 1980 to 2000 show that, whilst other relationships are similar, gradually a higher number of school trips among children in 2000 were associated with an increase in the number of non-school trips. This shows that, in the last two decades, children in the Osaka metropolitan area have increased the efficiency of their trip patterns by chaining extra trips onto their school trips.

The results also show that over the past 20 years, boys in comparison to girls have reduced their spent time on non-school activities and tended to spend their non-school activity in fewer locations. The difference on time spent between the genders on out-of-home non-school activities is getting smaller overtime. Interestingly, the estimation results also show that over the last 20 years the younger children (5-9 years old) have increased the number of their non-school trips but spent much less time on non-school activities than older children. Moreover, unlike their western counterparts, girls were not found to be chauffeured in cars more often in Japan. Rather, it was boys who were taken by car more often. Without further analysis into trip purpose it is hard to explain why this might be.

Nevertheless, the results also show that the increase of travel participation and the increase of trip chaining efficiency of children are likely due to the superb access of Osaka metropolitan area's public transport that has allowed public transport users, including children, to engage in more activities and pursue complex commutes with non-work/school activities. Policy that aims to relieve adults from chauffeuring burdens, increase children's daily physical activity, or improve their independent travel should strongly take into consideration the evidence presented here that showed 
over several decades and high car ownership growth rates that a built environment with mixed use and strong public transport can achieve such goals.

It should be repeated that this study did not include income levels and education levels of parents which the authors believe may play a role in influencing parents and children's attitude to walking and cycling and improve the models' explanatory powers. Due to the limitation of the datasets used, it was also not possible to examine the impacts of parental attitudes and fears related to traffic or strangers and do separate analysis for children who can drive (older than 18 years old). This will remain as a possible future research direction.

But overall, the results show that, overtime, more urban built environments, better accessibility by rail (to employment, stores, and other people), and a higher number of school trips have consistently reduced the amount of private car trips among children, however, a longer school duration, more non-school trips and a higher number of trip chains have consistently increased the proportion of children's travel by private car over three observed decades.

\section{Acknowledgements}

This research has been supported by EASTS International Research Group at "Sustainable neighbourhood and quality of live in developing countries" (IRG-10). The earlier version of this work has been submitted for presentation at the 2011 EASTS Conference, Jeju, Korea. The authors would like to thanks the anonymous reviewers for their constructive comments to the earlier version of this paper.

\section{References}

Alton, D., Adab, P., Roberts, L., Barrett, T., 2007. Relationship between walking levels and perceptions of the local neighbourhood environment. Archives of Disease in Childhood 92, 29-33.

Babey, S.H., Hastert, T.A., Huang, W., Brown, E.R., 2009. Sociodemographic, family, and environmental factors associated with active commuting to school among US adolescents. Journal of Public Health Policy 30, 203-220.

Bagley, M.N., Mokhtarian, P.L., 2002. The impact of residential neighborhood type on travel behavior: a structural equations modeling approach. The Annals of Regional Science 36, 279-297.

Bamberg, S., 2006. Is a residential relocation a good opportunity to change people's travel behavior? Results from a theory-driven intervention study. Environment and Behavior 38, 820-840.

Baslington, H., 2008. Travel socialisation: A social theory of travel mode behaviour. International Journal of Sustainable Transportation 2 (2), 91-114.

Bianchi, S.M., 2000. Maternal employment and time with children: dramatic change or surprising continuity? Demography 37, 401-414.

Cao, X.Y., Mokhtarian, P.L., Handy, S.L., 2009. The relationship between the built environment and nonwork travel: a case study of Northern California. Transportation Research Part A 43 (5), 548-559.

Choo, S., Mokhtarian, P.L., 2005. Do telecommunications affect passenger travel or vice versa? Structural equation models of aggregate US. Time Series Data Using Composite Indexes. Transportation Research Record 1926, 224-232.

Copperman, R.B., Bhat, C.R., 2007. Exploratory analysis of children's daily time-use and activity patterns: child development supplement to US. Panel Study of Income Dynamics. Transportation Research Record 2021, 36-44.

Courgeau, D., 1985. Interaction between spatial mobility, family and career lifecycle: a French survey. European Sociological Review 1, 139-162.

Ewing, R., Cervero, R., 2010. Travel and the built environment: a meta-analysis. Journal of the American Planning Association 76 (3), 265-294.

Frank, L., Kerr, J., Chapman, J., Sallis, J., 2007. Urban form relationships with walk trip frequency and distance among youth. American Journal of Health Promotion 21, 305-311.

Fukui, K., 2003. Longitudinal Analysis of Travel Behavior Change Using Dynamic Urban Area Classification. MS thesis, Department of Civil Engineering Systems, Kyoto University, Kyoto (February).

Fyhri, A., Hjorthol, R., 2009. Children's independent mobility to school, friends and leisure activities. Journal of Transport Geography 17 (5), 377-384.

Golob, T.F., 2003. Structural equation modeling for travel behavior research. Transportation Research B 37 (1), 1-25.

Hägerstrand, T., 1970. What about people in regional science? Papers of the Regional Science Association 24, 7-21
Handy, S., Cao, X., Mokhtarian, P., 2005. Correlation or causality between the built environment and travel behavior? Evidence from Northern California. Transportation Research D 10 (6), 427-444.

Hillman, M., Adams, J., Whitelegg, J., 1990. One False Move... A Study of Children's Independent Mobility. Policy Studies Institute, London.

Hjorthol, R., Fyhri, A., 2009. Do organized leisure activities for children encourage car-use? Transportation Research Part A 43 (2), 209-218.

Hollingworth, B.J., Miller, E.J., 1996. Retrospective interviewing and its application in study of residential mobility. Transportation Research Record 1551, 74-81.

Jones, P.M., 1979. New approach to understanding travel behaviour: the human activity approach. In: Hensher, D.A., Stopher, P.R. (Eds.), Behavioural Travel Modelling. Groom Helm, London, pp. 55-80.

Kitamura, R., Susilo, Y.O., 2005. Is travel demand is insatiable? A study of changes in structural relationships underlying travel. Transportmetrica 1, 23-45.

Kitamura, R., Mokhtarian, P., Daidet, L., 1997. A micro-analysis of land use and travel in five neighbourhoods in the San Francisco Bay Area. Transportation 24, 125158

Kitamura, R., Susilo, Y.O., Fukui, K., Murakami, J., Kishino, K., 2003. The invariants of travel behavior: the case of Kyoto-Osaka-Kobe metropolitan area of Japan, 1970-2000. In: Paper presented at the 10th conference of the international association for travel behaviour research, Lucerne (August).

Lanzendorf, M., 2003. Mobility biographies: a new perspective for understanding travel behaviour. In: Paper presented at the 10th international conference on travel behaviour research, Lucerne (August).

Library of Congress, 1994. The Country Studies Series by Federal Research Division. <http://www.country-data.com/cgi-bin/query/r-7144.html>.

Lin, J.J., Chang, H.T., 2010. Built environment effects on children's school travel in Taipei: independence and travel mode. Urban Studies 47, 867-889.

McDonald, N.C., 2006. Exploratory analysis of children's travel patterns. Transportation Research Record 1977, 1-7.

McDonald, N.C., 2007. Travel and the social environment: evidence from Alameda County, California. Transportation Research Part D 12 (1), 53-63.

McDonald, N.C., 2008. Household interactions and children's school travel: the effect of parental work patterns on walking and biking to school. Journal of Transport Geography 16 (5), 324-331.

McMillan, T.E., 2007. The relative influence of urban form on a child's travel mode to school. Transportation Research Part A 41, 69-79.

Mercado, R., Páez, A., 2009. Determinants of distance traveled with a focus on the elderly: a multilevel analysis in the Hamilton CMA. Canada. Journal of Transport Geography 17 (1), 65-76.

Mitra, R., Buliung, R.N., Roorda, M.J., 2010. The built environment and school travel mode choice in Toronto, Canada. Transportation Research Record 2156, 2150 2159.

Naess, P., 2006. Urban Structure Matters: Residential Location, Car Dependence and Travel Behaviour. The RTPI Library Series No. 13, Routledge.

Páez, A., Mercado, R.G., Farber, S., Morency, C., Roorda, M., 2010. Relative accessibility deprivation indicators for urban settings: definitions and application to food deserts in Montreal. Urban Studies 47 (7), 1415-1438.

Page, A.S., Cooper, A.R., Griew, P., Davis, L., Hillsdon, M., 2009. Independent mobility in relation to weekday and weekend physical activity in children aged 1011 years: the PEACH project. International Journal of Behavioral Nutrition and Physical Activity 6 (2), 1-9.

Simma, A., Axhausen, K.W., 2003. Commitments and modal usage: analysis of German and Dutch panels. Transportation Research Record 1854, 22-31.

Sjolie, A.N., Thuen, F., 2002. School journeys and leisure activities in rural and urban adolescents in Norway. Health Promotion International 17, 21-30.

Sorenson, A., 2002. Making of Urban Japan: Cities and Planning from Edo to the Twenty-first Century. Routledge, New York

Stefan, K.J., Hunt, J.D., 2006. Age-based analysis of travel by children in Calgary, Canada. In: Anon (Ed.), Transportation Research Board 2006 Annual Meeting, Washington, DC. Paper \#06-2832 (January).

Strathman, J.G., Dueker, K.J., 1995. Understanding Trip Chaining. Special Reports on Trip and Vehicle Attributes, 1990 NPTS Report Series, US Department of Transportation

Sun, Y., Waygood, E., Fukui, K., Kitamura, R., 2009. Built environment or household life-cycle stages: which explains sustainable travel more? Transportation Research Record 2135, 123-129.

Susilo, Y.O., 2010. In: Moshe, Givoni, David, Banister (Eds.), Integrating Individual Travel Desires in Transport Planning, at Integrated Transport: From Policy to Practice. Routledge, London, pp. 139-161.

Susilo, Y.O., Dijst, M., 2009. How far is too far? Travel time ratios for activity participations in the Netherlands. Transportation Research Record 2134, 89-98.

Susilo, Y.O., Dijst, M., 2010. Behavioural decisions of travel-time ratio for work, maintenance and leisure activities in the Netherlands. Journal of Transportation Planning and Technology 33, 19-34.

Susilo, Y.O., Kitamura, R., 2008. Structural changes in commuters' daily travel: the case of auto and transit commuters in the Osaka metropolitan area of Japan, 1980 through 2000. Transportation Research A 42, 95-115.

Susilo, Y.O., Maat, K., 2007. The influence of built environment to the trends in commuting journeys in the Netherlands. Transportation 34, 589-609.

Susilo, Y.O., Axhausen, K.W., 2007. How firm are you? A study of the stability of individual activity-travel-location pattern using Herfindahl Index. In: The 11th World Conference on Transport Research, Berkeley, CA, USA 
Susilo, Y.O., Williams, K., Lindsay, M., Dair, C., 2010. Does green in mean green out? An exploration of individual travel patterns and the influences of their environmental preferences in the UK "Sustainable Neighbourhoods". In: The 89th Annual Meeting of Transportation Research Board, Washington, DC, USA.

Timperio, A., Crawford, D., Telford, A., Salmon, J., 2004. Perceptions about the local neighbourhood and walking and cycling among children. Preventive Medicine $38,39-47$.

Valentine, G., McKendrick, J., 1997. Children's outdoor play: exploring parental concerns about children's safety and the changing nature of childhood. Geoforum 28 (2), 219-235.
Waygood, E.O.D., 2009. Keeping It Close: Why Compact Development Helps Children Travel. Kyoto University.

Waygood, E.O.D., 2011. What is the role of mothers in transit-oriented development? The case of Osaka-Kyoto-Kobe. In: Proceedings of the Fourth International Conference on Women's Issues in Transportation, vol. 2. Technical Papers, Irvine, California.

Waygood, E.O.D., Kitamura, R., 2009. Children in a rail-based developed area of Japan. Transportation Research Record 2125, 36-43.

Waygood, E.O.D., Susilo, Y.O., 2011. East or west, does it matter? Comparison of children activity-travel behaviours in the UK and Japan. In: The 2011 Eastern Asia Society for Transportation Studies Conference, Jeju, Korea. 